\title{
Long-term Outcome of Infantile Gratification Phenomena
}

\author{
Mohammed M. Jan, Mohammed H. Al Banji, Baraa A. Fallatah
}

\begin{abstract}
Background: Infantile gratification phenomena are self-stimulatory behaviors that are often misdiagnosed as epilepsy. Although the prognosis is thought to be benign, limited long-term follow-up studies exist. This was the objective of our study in addition to exploring the risks of future developmental, behavioral, or neurological abnormalities. Methods: Series of consecutive infants with gratification phenomena were identified both retrospectively and prospectively over an eight year period from a single pediatric neurology service. The diagnosis was based on descriptive history, review of videotaped events, lack of neurological or developmental abnormalities, and normal routine electroencephalogram. Results: Nineteen infants were followed for 3-11 years (mean 7.1). Their ages ranged between $4-13$ months (mean 7) with $79 \%$ females. The diagnosis was not reached by the referring physician and $74 \%$ were misdiagnosed as epilepsy or movement disorder. The episodes recurred with variable frequency with gradual reduction in number and increase in length of attack-free periods with advancing age. Complete remission was noted in all patients by age 1-3 years (mean 1.9). However, 4 children $(21 \%)$ developed features of attention deficit hyperactivity disorders (ADHD) on long-term follow up. In this group, the gratification phenomena appeared at a younger age with higher attack frequency. Conclusions: Gratification phenomena in infants are benign and self-limited, often spontaneously disappearing by two years of age. A correlation with future ADHD was found; however, larger prospective studies are needed to further examine this possible association.
\end{abstract}

RÉSUMÉ: Résultat à long terme du phénomène d'auto-stimulation sexuelle infantile. Contexte : Le phénomène d'auto-stimulation sexuelle infantile consiste en des comportements d'auto-stimulation qui sont souvent diagnostiqués de façon erronée comme étant de l'épilepsie. Bien que le pronostic soit considéré comme bénin, il existe peu d'études de suivi à long terme chez ces enfants. Ceci constitue donc l'objectif de notre étude en plus d'explorer les risques d'anomalies futures du développement, du comportement ou d'anomalies neurologiques. Méthode : Nous avons identifié rétrospectivement et prospectivement des séries consécutives de nourrissons présentant ce phénomène au cours d'une période de 8 ans dans un même service de neurologie pédiatrique. Le diagnostic était fondé sur une histoire descriptive, une revue des événements qui avaient été enregistrés sur bandevidéo, une absence d'anomalies neurologiques ou du développement et un électroencéphalogramme de routine normal. Résultats : Nous avons identifié 19 nourrissons qui avaient été suivis pendant une période de 3 à 11 ans (moyenne 7,1 ans). Ils étaient âgés de 4 à 13 mois (moyenne 7 mois) au moment de la consultation initiale et $79 \%$ étaient des filles. Le médecin référant n'avait pas posé le diagnostic et un diagnostic erroné d'épilepsie ou de trouble du mouvement avait été posé dans $74 \%$ des cas. La fréquence des épisodes était variable et diminuait graduellement en nombre avec l'âge, alors que le temps entre les épisodes s'allongeait progressivement. Une rémission complète a été notée chez tous les enfants entre l'âge de 1 et 3 ans (moyenne 1,9 ans). Cependant, 4 enfants (21\%) ont présenté des manifestations de troubles d'hyperactivité avec déficit de l'attention au cours du suivi à long terme. Dans ce groupe, le phénomène d'auto-stimulation était apparu à un âge plus précoce et il était plus fréquent. Conclusions : Le phénomène d'autostimulation sexuelle chez les nourrissons est bénin et disparaît spontanément, souvent avant l'âge de 2 ans. Nous avons observé une corrélation avec la présence éventuelle de troubles d'hyperactivité avec déficit de l'attention. Cependant ceci mérite d'être étudié davantage par des études prospectives portant sur un plus grand nombre de sujets.

Can J Neurol Sci. 2013; 40: 416-419

Gratification phenomena in infants, also known as infantile masturbation, are self-stimulatory behaviors that have tendency to become a habit ${ }^{1}$. They are generally not well recognized by general practitioners and pediatricians, resulting in misdiagnoses that often include epilepsy, recurrent abdominal pain, and paroxysmal dystonia or dyskinesia ${ }^{1}$. Gratification phenomena may begin from very early age, typically after two to three months of age ${ }^{2,3}$. Stereotypic motor manifestations include lower limbs scissoring posture and repetitive pelvic movements with rubbing the thighs together and rocking the genital region against the bed or other objects, such as the infant seat or its belt ${ }^{4-6}$. The paroxysmal movements are typically associated with grunting, facial flushing, and irregular breathing, which are all followed by sweating and exhaustion. The infant may not appear completely responsive with distant gaze, but the behavior can be interrupted by distraction. If interrupted, the infant will become annoyed and resist stopping. The diagnosis is based on a descriptive history, visual review of the event, lack of neurological or developmental abnormalities, and normal

\footnotetext{
From the Department of Pediatrics, Faculty of Medicine, King Abdulaziz University, Jeddah, Kingdom of Saudi Arabia.

Received September 17, 2012. Final Revisions Submitted November 1, 2012. Correspondence to: Mohammed M.S. Jan, Pediatric Neurology, Department of Pediatrics, Faculty of Medicine, King Abdulaziz University, PO Box 80215, Jeddah 21589, Kingdom of Saudi Arabia. Email: mmjan@kau.edu.sa.
} 
investigations ${ }^{3}$. Gratification phenomena tend to improve with age, particularly after reassuring the anxious parents. Although the prognosis is thought to be benign, limited long-term followup studies exist ${ }^{7}$. This was the objective of our study in addition to exploring the risks of future developmental, behavioral, or neurological abnormalities.

\section{Methods}

Series of consecutive infants with gratification phenomena were identified both retrospectively and prospectively over an eight year period ending the 1st of January 2009. Patients were identified through referrals and consultations to one pediatric neurology service at King Abdulaziz University Hospital and King Faisal Specialist Hospital and Research center, both in Jeddah, Kingdom of Saudi Arabia. King Abdulaziz University Hospital is the main teaching center of the western region. The author also provided consulting services at King Faisal Specialist Hospital and Research center. Both are multispecialty adult and pediatric hospitals providing tertiary medical care for most of the regional population of western Saudi Arabia. The study design and follow up interviews were approved by the hospital ethics committee and all contacted parents consented for the study. Clinical data were collected during the initial visit and by chart review. Gratification phenomena were diagnosed based on descriptive history, review of videotaped events, lack of neurological or developmental abnormalities, and normal routine electroencephalogram (EEG). Only patients with documented typical events on videotapes and normal EEG were included. Follow-up by one pediatric neurologist was performed to document the development of any neurological, developmental, or behavioral abnormalities. This was conducted during followup clinic visits or by telephone interviews.

\section{RESULTS}

Nineteen consecutive infants with gratification phenomena met the admission criteria. The majority (79\%) were females with a female to male ratio of 3.75:1. The referral diagnosis was epilepsy in eight (42\%), movement disorder in six (32\%), and no diagnosis in five $(26 \%)$ patients. The self-stimulatory nature of this behavior was not identified by the referring physician. The age of onset ranged from 4-13 months (mean 7). The attacks usually occurred when the infant was put down for sleep or when he/she was not attended to. They never occurred during sleep, upon awakening, feeding, or playtime. Video recordings of the events were reviewed by one author in all cases. Most of these videos (17/19) were recorded at home by the parents and two infants had in-hospital video EEG recordings. They were referred with "intractable epilepsy" that failed multiple antiepileptic drugs. The frequency of the events was variable ranging from daily to weekly. In some infants, the attacks occurred every time the infant was put down for sleep. The duration of the events was usually prolonged lasting for 5-15 minutes and sometimes for up to half an hour. Initial neurological and developmental evaluations were age appropriate in all infants. Family history was negative for similar events. Twelve children (63\%) had neuroimaging prior to our assessment, computerized tomography in three and magnetic resonance imaging (MRI) in nine, with no reported abnormalities. None had epileptiform discharges on routine
EEG. Eight infants had chloral hydrate sedation for these recordings. Six patients were placed on an antiepileptic drug prior to our evaluation. Once the diagnosis was established, the parents were reassured and no further drug treatment was provided. The children were slowly weaned off the antiepileptic drugs.

The infants were followed for 3-11 years (mean 7.1). Most families $(68 \%)$ were contacted by telephone because they failed to show for follow-up clinic appointments. The episodes recurred with variable frequency with gradual reduction in number and increase in length of attack-free periods with advancing age. Complete remission was noted in all patients by age 1-3 years (mean 1.9). However, four children (21\%) developed features of attention deficit hyperactivity disorders (ADHD) on long-term follow up. This was confirmed by a clinical visit and application of the Diagnostic and Statistical Manual of Mental Disorders, 4th Edition criteria. One girl had the inattentive type, one boy had the hyperactive/impulsivity type, and one boy and one girl had the combined type. None of the children were on drug treatment for these symptoms at the time of our evaluation. In this group, the gratification phenomena appeared at a younger age with higher attack frequency, but this did not reach statistical significance. No other subsequent developmental, neurological, or behavioral abnormalities were noted on follow-up interviews.

\section{Discussion}

This study described the clinical features, course, and outcome of infants with gratification phenomena. Although masturbation is a normal behavior in older children and adolescence, occurring in up to $90 \%$ of males and $60 \%$ of females at some point in their lives, it is exceedingly uncommon in infants ${ }^{8}$. In infants, this masturbation-like behavior can be difficult to recognize due to the absence of direct genital manipulation, as well as the variable manifestations. The majority of our infants were females which is consistent with previous literature 9,10 . This also suggests that the gratification phenomena in infants may be different from a simple masturbation behavior, which is more common in boys. Although it seems that it provides some gratification and superficially simulates masturbation, it becomes more of a habit when the infant is sleepy or bored. Several theories were previously suggested to explain such unusual behavior in infancy ${ }^{10,11}$. These include, sleep disorder, genito-urinary irritation, and early weaning from breast-feeding ${ }^{10}$. Other authors suggested a correlation with emotional deprivation, neglect, and abuse ${ }^{11}$. Therefore, psychosocial stresses including the birth or loss of a sibling or separation from a parent should be excluded. Although these theories and possible contributing factors could be relevant in some cases, they are extremely uncommon in our practice. In normal infants with gratification phenomena the exact mechanism remains unknown in most cases.

Our results suggest that gratification phenomena are frequently missed or misdiagnosed as epilepsy or movement disorder. The paroxysmal tightening of the thighs, rocking pelvic movements, mechanical pressure applied to the genital area, grunting, facial flushing, irregular breathing, and sweating during the event, can be easily misinterpreted as seizures ${ }^{12,14}$. 
Table: Differentiation between infantile gratification phenomena and seizures

\begin{tabular}{l|l|l}
\hline Clinical Features & Gratification Phenomena & Seizures \\
\hline Age of onset & Usually after 2-3 months & Any age \\
\hline Age of remission & Usually before 3 years & Variable \\
\hline State & When not attended to or upon falling asleep, never in sleep & Random occurrence, may be more often in sleep \\
\hline Onset & No aura or evolution & May have an aura and frequently evolve or spread \\
\hline Features & $\begin{array}{l}\text { Facial flushing, grunting, diaphoresis, pressure on the } \\
\text { perineum with posturing and rubbing of the lower limbs }\end{array}$ & $\begin{array}{l}\text { Tonic, rhythmic clonic, or myoclonic motor phenomena, } \\
\text { may have facial twitching }\end{array}$ \\
\hline Loss of consciousness & Never (may appear abnormal) & Frequently abnormal \\
\hline Cyanosis & Never & May be present \\
\hline Duration & Usually long (up to 30 min) & Few minutes (rarely $>10 \mathrm{~min})$ \\
\hline Termination & Can be interrupted by distraction & Cannot be interrupted \\
\hline After the event & Usually falls asleep or look exhausted & Postictal confusion, weakness, aphasia, or headache \\
\hline Examination & Always normal & Can be abnormal \\
\hline Electroencephalogram & Always normal & Usually abnormal \\
\hline
\end{tabular}

This misdiagnosis may lead to unnecessary investigations or antiepileptic drug treatment, which was the case in many of our patients. This will lead to further parental anxiety and distress ${ }^{15}$. The differentiation between gratification phenomena and seizures can be achieved by careful history and review of video recorded events (Table). Other authors suggested several diagnostic criteria that included; 1) onset after the age of three months and before three years; 2) stereotyped episodes of variable duration; 3) vocalizations with quiet grunting; 4) facial flushing with diaphoresis; 5) pressure on the perineum with characteristic posturing of the lower extremities; 6) no alteration of consciousness; 7) cessation with distraction; 8) normal examination; and 9) normal laboratory studies ${ }^{3}$. However, detailed investigations, EEG, or neuroimaging are not necessary. Video-taping the event by the care giver and increased awareness of general practitioners and pediatricians are needed for early recognition.

In our study, only parental reassurance was provided and no further drug treatment was given. This reassurance is crucial since parents and relatives are often frightened by the unexpected appearance and occasional high frequency of these attacks. Recurrence with variable frequency and duration is the rule. Some of our patients had daily attacks occurring every time the infant would be put to sleep. Other authors reported an event frequency ranging between 12/day to 1 /week (mean 16/week) with a duration ranging between 30 seconds to 2 hours (mean nine minutes), a feature that helps differentiating it from seizures ${ }^{4}$. The parents should be educated that this is a behavioral variation that has a tendency to become a habit. They need to know that it is harmless, not painful, and reassured that it will eventually subside with time. We usually instruct them to try to interrupt it by distraction and engagement in other activities or play. Scolding or threatening the infant is not appropriate as efforts to stop the behavior forcefully will only reinforce it and possibly instill a sense of shame or wrong-doing as the infants gets older. Referral to behavioral psychology may be beneficial for some parents. Most of our families (68\%) did not attend any follow-up visits after they were informed about the nature of the diagnosis. This is most likely because they were reassured, however, it could also be the result of stigma of such diagnosis. In fact, some parents may become offended and often seek a second opinion. In our practice, we avoid using the term "masturbation" and describe it as a gratifying "behavior" that evolved into a "habit".

Our infants were followed for up to 11 years (mean 7.1) with gradual reduction in attack frequency. We noted complete remission before three years of age, which is consistent with previous reports. Limited literature is available regarding the long-term follow-up of children with gratification phenomena. One outcome study with two years follow-up revealed that infants rarely continue to have gratification phenomena beyond the age of two years ${ }^{7}$. Four of our children (21\%) developed features suggestive of ADHD, which is much higher than the prevalence figures in our region that do not exceed $6 \%$ of normal pre-school children ${ }^{16,17}$. These infants tended to be younger of age at onset and had higher attack frequency. The possible association between gratification phenomena and ADHD was not previously reported. Children with ADHD are known to have inhibitory deficits and tendency for addicting behaviors ${ }^{18}$. In fact, two previous studies reported excessive masturbation in children with ADHD ${ }^{19,20}$. Symptoms of ADHD are not usually apparent in infants, possibly because of their limited motor and cognitive abilities. We propose a possible link with gratification phenomena, which could be an early feature or a predictor of future ADHD. However, larger prospective studies are needed to further study this possible association.

\section{REFERENCES}

1. Nechay A, Ross LM, Stephenson JBP, O'Regan M. Gratification disorder ("infantile masturbation"): a review. Arch Dis Child. 2004;89:225-6.

2. Meizner I. Sonographic observation of in utero fetal "masturbation". J Ultrasound Med. 1987;6:111.

3. Yang ML, Fullwood E, Goldstein J, Mink JW. Masturbation in infancy and early childhood presenting as a movement disorder: 12 cases and a review of the literature. Pediatrics. 2005;116 (6): $1427-32$.

4. Fleisher DR, Morrison A. Masturbation mimicking abdominal pain or seizures in young girls. J Pediatr. 1990;116:810-4. 
5. Mink JW, Neil JJ. Masturbation mimicking paroxysmal dystonia or dyskinesia in a young girl. Mov Disord. 1995;10:518-20.

6. Bakwin H. Erotic feelings in infants and young children. Am J Dis Child. 1973;126:52-4.

7. Unal F. The clinical outcome of childhood masturbation. Turk $\mathbf{J}$ Pediatr. 2000;42(4):304-7.

8. Leung AK, Robson WL. Childhood masturbation. Clin Pediatr. 1993;32:238-41.

9. Bradley SJ. Childhood female masturbation. Can Med Assoc J. 1985;132:1165-6.

10. Unal F. Predisposing factors in childhood masturbation in Turkey. Eur J Pediatr. 2000;159:338-42.

11. McCray GM. Excessive masturbation of childhood is a symptom of tactile deprivation? Pediatrics. 1978;62:277-9.

12. Bower B. Fits and other frightening or funny turns in young children. Practitioner. 1981;225:297-304.

13. Shuper A, Mimouni M. Problems of differentiation between epilepsy and non-epileptic paroxysmal events in the first year of life. Arch Dis Child. 1995;73:342-4.

14. Livingston S, Berman W, Pauli LL. Masturbation simulating epilepsy. Clin Pediatr. 1975;14:232-4.
15. Franic T, Franic IU. Infantile masturbation - eclusion of severe diagnosis does not exclude parental distress - case report. Psychiatria Danubina. 2011;23(4):398-9.

16. Jenahi E, Khalil MS, Bella H. Prevalence of attention deficit hyperactivity symptoms in female schoolchildren in Saudi Arabia. Ann Saudi Med. 2012;32(5):462-8

17. Alqahtani MM. Attention-deficit hyperactive disorder in schoolaged children in Saudi Arabia. Eur J Pediatr. 2010;169(9): 1113-7.

18. Dalen L, Sonuga-Barke EJ, Hall M, Remington B. Inhibitory deficits, delay aversion and preschool AD/HD: implications for the dual pathway model. Neural Plast. 2004;11(1):1-11.

19. Bilgic A, Gurkan K, Turkoglu S. Excessive masturbation and hypersexual behavior associated with methylphenidate. J Am Acad Child Adolesc Psychiatry. 2007;46(7):789-90.

20. Ogasawara M, Takeda M. Attention deficit disorder without hyperactivity, (excessive) masturbation, nail biting/ onchophagia, nose picking/rhinotillexomania, finger sucking. Ryoikibetsu Shokogun Shirizu. 2003;(40):92-4. 